\title{
PENGARUH TEKNIK SANDWICH TERHADAP KEBOCORAN TEPI PADA RESTORASI KAVITAS KELAS II
}

\author{
I G A A Hartini ${ }^{1}$, Sumantri ${ }^{2}$, Yessy Angelina ${ }^{3}$ \\ ${ }^{1,2}$ Bagian Konservasi Gigi, Fakultas Kedokteran Gigi Universitas Mahasarawati Denpasar \\ ${ }^{3}$ Mahasiswa Tingkat Sarjana, Fakultas Kedokteran Gigi Universitas Mahasarawati Denpasar \\ e-mail: gekhartini@gmail.com
}

\begin{abstract}
The edge microleakage is one factor in the failure of the restoration. Edge microleakage may be reduced by using Glass ionomer cement as a base in sandwich technique restorations. Glass ionomer cement attaches chemically to the chemical adhesion, has good biocompatibility, the coefficient of thermal expansion is the same as the tooth structure, the dimensions are stable and the shrinkage process is minimal when setting, so that it may produce good edge closure. The aimed of this study was to evaluate the effect of sandwich techniques to avoid edge microleakage in class II cavity restorations. Twenty extracted human mandibular first premolars were made Class II DO cavities and divided into two groups. Ten teeth in the first group were restored with sandwich techniques, while the second group was restored with composite resin without sandwich technique. Both groups were immersed in a disclosing agent solution for 24 hours. After that the sample is cleaned and cut in the middle of the restoration (mesiodistal) with diamond disk and observations of the dye penetration length are done visually. Data were analyzed statistically by independent $t$-test $(p<0.05)$. The results obtained showed that there was a significant difference between the sandwich restoration group and the restoration without sandwich techniques against edge leakage in class II cavities.
\end{abstract}

Keywords: edge microleakage, sandwich technique restorations, glass ionomer cement

\section{PENDAHULUAN}

Restorasi gigi merupakan penggantian jaringan keras gigi yang telah rusak dengan bahan yang diletakkan pada gigi dalam waktu yang tidak terbatas. Menurut Yuni (2007), pembuatan suatu restorasi bertujuan untuk mencegah lanjutnya kerusakan gigi sehingga gigi dapat dipertahankan selama mungkin di dalam rongga mulut. ${ }^{1}$ Bahan resin komposit dapat digunakan untuk gigi anterior maupun posterior dan menjadi pilihan dalam prosedur restorasi rutin para dokter gigi. Resin komposit ini tidak selalu dapat diaplikasikan pada semua kondisi kerusakan jaringan keras gigi, salah satunya pada daerah operasi yang tidak dapat dikontrol kelembabannya seperti pada kavitas dengan dinding gingival terletak di pada cementoenamel junction (CEJ). Resin komposit dalam suasana lembab akan mengalami degradasi secara kimiawi oleh enzim hidrolisis yang akhirnya dapat menimbulkan kebocoran restorasi dan memicu terjadinya karies sekunder. Kekurangan lainnya yaitu adanya pengkerutan selama proses polimerisasi dapat menyebabkan terjadinya kehilangan kontak antara resin komposit dengan dinding kavitas sehingga mengakibatkan pembentukan celah pada tepi restorasi. Daerah yang sangat rentan terhadap kebocoran tepi tersebut terdapat pada dinding gingival daerah proksimal pada restorasi kelas II, karena sisa email yang sedikit ataupun tidak adanya email, sehingga diperlukan teknik restorasi yang khusus untuk kavitas ini. ${ }^{1,2}$ Restorasi sandwich merupakan teknik restorasi yang menggunakan dua bahan restorasi yang berbeda dalam satu restorasi seperti pemakaian glass ionomer cement dan resin komposit ataupun glass ionomer cement dan amalgam. Semen ini berikatan secara kimia pada dentin dan mempunyai koefien ekspansi termal yang sama dengan struktur gigi.

Penelitian ini bertujuan untuk mengetahui pengaruh teknik sandwich terhadap kebocoran tepi pada restorasi kelas II. Penelitian ini juga dimaksudkan sebagai dasar acuan untuk dalam memilih teknikrestorasi kelas II yang dapat menghasilkan penutupan kebocoran tepi yang lebih baik, sebagai dasar penelitian lebih lanjut mengenai teknik restorasi sandwich dan kebocoran tepi pada restorasi gigi.

\section{RESIN KOMPOSIT}

Resin komposit merupakan bahan yang kompleks, yang terdiri dari gabungan komponen organik yang berupa matriks polimer resin yang lunak dan bahan pengisi (filler) inorganik yang keras. Umumnya matriks resin dijumpai dalam bentuk BisGMA (bisphenol A-glycidyl methacrylate), UDMA (Urethane-dimethacrylate) dan TEGDMA (triethylene glycol dimethacrylate). ${ }^{3}$ Selain mengandung matrik resin dan partikel pengisi sebagai kandungan utama, resin komposit juga memiliki kandungan lainnya untuk meningkatkan efektivitas dan ketahanan bahan, yaitu coupling agent, inisiator, akselerator, pigmen, inhibitor polimerisasi dan stabilisator. Coupling agent yang digunakan adalah silane. Silane ini dipergunakan untuk mengikat partikel pengisi dengan matriks resin sehingga memungkinkan terjadinya distribusi tekanan saat resin komposit menerima beban. Inisiator dan akselerator dibutuhkan untuk memungkinkan terjadinya proses polimerisasi. Komposisi lainnya yaitu pigmen, 
mengingat resin komposit merupakan bahan restorasi gigi yang memerlukan pilihan warna yang bervariasi. ${ }^{4}$ Lutz dan Phillips (1983), mengklasifikasikan komposit resin berdasarkan ukuran partikel filler dan distribusinya, yaitu macrofilled, microfilled dan hybrid composites. $^{5}$

a. Macrofilled composites. Resin komposit makrofilled merupakan resin komposit generasi pertama, yang dikenal juga sebagai resin komposit tradisional atau resin komposit konvensional. Komposit ini memiliki daya tahan yang cukup baik terhadap fraktur, warna yang stabil, susah dipoles dan menghasilkan permukaan yang kasar, sehingga makrofilled komposit jarang digunakan.

b. Microfilled composites. Resin komposit microfilled dikembangkan untuk memperbaiki sifat macrofilled komposit. Daya tahan terhadap fraktur rendah, dapat dipoles dengan sangat baik serta mengkilat, dan warnanya lebih stabil.

c. Hybrid composites. Komposit ini memiliki daya tahan terhadap fraktur yang yang baik, dapat dipoles dengan baik dan warnanya stabil. Resin komposit tipe ini mengandung 2 macam filler yaitu partikel makrofil dengan penambahan partikel mikrofil, sehingga baik digunakan pada gigi anterior maupun posterior.

Resin komposit tidak berikatan secara kimia dengan enamel gigi, melainkan berikatan secara mekanis dengan pengetsaan dan pengapliakasian bahan bonding. Bounocore menyatakan bahwa untuk mendapatkan ikatan antara jaringan gigi dan bahan tumpatan resin komposit secara mekanis maka email dietsa terlebih dahulu dengan asam fosfat 30-50\% selama 30 detik. ${ }^{4}$ Metode ini telah digunakan secara luas untuk menciptakan ikatan fisis antara resin dengan jaringan gigi. Pengetsaan email ini akan menyebabkan terbentuknya pori-pori yang akan dialiri oleh resin yang belum mengeras dan berpolimerisasi di dalam pori tersebut sehingga tercipta retensi mekanis yang cukup bagus. Selama ini banyak dilakukan penyelidikan penggunaan lapisan dentin bonding agent yang diaplikasikan antara dentin dengan resin komposit dengan maksud untuk menciptakan ikatan antara dentin dengan resin komposit tersebut. ${ }^{6}$

Keuntungan dari restorasi resin komposit ini yaitu tumpatan resin komposit memiliki estetis yang baik, radiopak, perlekatan mekanik yang baik pada struktur gigi dan konduktivitas suhu yang rendah. Kekurangan dari restorasi resin komposit yaitu timbulnya celah mikro yang memicu terjadinya karies sekunder yang disebabkan karena proses pengkerutan selama polimerisasi, keausan permukaan oklusal yang signifikan,harga relatif mahal dan memerlukan teknik yang cukup rumit. ${ }^{7}$

\section{GLASS IONOMER CEMENT}

Glass ionomer cement (GIC) pertama kali diperkenalkan oleh Wilson dan Kent pada tahun 1972.
Bahan ini terdiri dari bubuk kaca fluoroaluminosilikat dikombinasikan dengan polimer dalam air atau asam. Komponen yang terjandung dalam bubuk kaca yaitu $\mathrm{SiO}_{2} \quad(35,2-41,9 \%), \quad \mathrm{Al}_{2} \mathrm{O}_{3} \quad(20,1-28,6 \%), \mathrm{AlF}_{3} \quad(1,6-$ $8,9 \%), \mathrm{CaF}_{2}(15,7-21,2 \%), \mathrm{Na}_{3} \mathrm{AlF}_{6}(4,1-9,3 \%), \mathrm{AlPO}_{4}$ $(3,8-12,1 \%)$, sedangkan cairannya terdiri dari air dan asam polialkenoat dalam bentuk kopolimer dengan asam itikonik, maleik dan campuran kompleks polimer akrilik dengan konsentrasi 40-50\%. ${ }^{7}$ Glass ionomer cement ini diklasifikasikan sesuai dengan fungsinya yang dikemukakan oleh Wilson dan McLean (1988) yaitu: Tipe 1 (Luting cement/semen perekat; Tipe 2 (Restorative cement/bahan tumpatan); Tipe 3 (Lining/basis/bahan pelapik).

Keuntungan restorasi dengan glass ionomer cement yaitu dapat melekat pada dentin secara kimia, memiliki biokompatibilitas yang baik, melepaskan fluor, dan koefisien. ekspansi termalnya sama dengan struktur gigi. Glass ionomer cement memiliki dimensi yang stabil dan proses pengkerutan yang minimal pada saat setting, sehingga dapat menghasilkan penutupan tepi yang baik..$^{5}$ Kerugian dari glass ionomer cement ini yaitu sensitif terhadap air pada proses pengerasan, resistensi yang buruk terhadap abrasi, estetik kurang baik, dan kekuatan tensilnya kurang. ${ }^{6}$

\section{KEBOCORAN MIKRO PADA RESTORASI RESIN KOMPOSIT}

Penutupan tepi restorasi yang baik dengan permukaan gigi sangat diperlukan untuk mengurangi kebocoran tepi dan resiko terjadinya karies sekunder. Pemakaian resin komposit telah dikembangkan selama bertahun-tahun, namun tetap sulit untuk mendapatkan penutupan marginal yang baik. Kegagalan yang sering terjadi disebabkan oleh adanya pengkerutan selama polimerisasi yang dapat disebabkan oleh kandungan resin, filler dan kekerasannya serta juga disebabkan oleh teknik pengaplikasian yaitu jumlah bahan yang diaktivasi, cara dan kecepatan polimerisasi serta arah penyinaran. Pengkerutan selama polimerisasi menyebabkan terjadinya kontraksi pada restorasi resin komposit dan dapat mengganggu penutupan tepi antara restorasi resin komposit dan struktur gigi. ${ }^{1}$ Daerah yang sangat rentan terhadap kebocoran mikro adalah dinding gingival pada restorasi kavitas kelas II dan V. Restorasi kelas II menimbulkan masalah yaitu perubahan warna dan kerusakan tepi restorasi terutama pada daerah cementoenamel junction. ${ }^{8}$

\section{RESTORASI SANDWICH GIC DAN RESIN KOMPOSIT}

Restorasi sandwich adalah suatu teknik restorasi dengan menggabungkan dua macam bahan yaitu glass ionomer cement dan resin komposit yang pertama kali diperkenalkan oleh Wilson dan McLean (1988). Teknik ini dikenal dengan istilah restorasi laminasi dengan menggunakan GIC sebagai bahan pengisi, yang memiliki biokompatibilitas, sifat fisik dan kekuatan perlekatan yang baik terhadap dentin. Penggabungan kedua bahan dalam satu restorasi ini bertujuan untuk 
mendapatkan suatu restorasi yang monolitik antara resin komposit, glass ionomer cement dan jaringan keras gigi.

${ }^{9}$ Restorasi sandwich dibedakan menjadi 2 macam, yaitu restorasi sandwich dengan teknik open (restorasi laminasi terbuka) dan restorasi sandwich dengan teknik closed (restorasi laminasi tertutup). Restorasi sandwich dengan teknik open merupakan indikasi pada kavitas kelas II dan kelas V dengan batas dinding gingival pada daerah cementoenamel junction (CEJ). Glass ionomer cement diaplikasikan pada dasar restorasi bagian proksimal dan resin komposit diaplikasikan di atasnya. Pada restorasi ini, glass ionomer cement pada bagian proksimal tidak terlindungi oleh resin komposit dan langsung berhubungan dengan lingkungan rongga mulut. Restorasi sandwich dengan teknik closed, glass ionomer cement dibuat sebagai basis pengganti dentin pada kavitas yang cukup dalam. Glass ionomer cement pada teknik ini terlindung oleh resin komposit diatasnya dan oleh dinding-dinding kavitas.

\section{BAHAN DAN METODE}

Jenis penelitian yang digunakan adalah penelitian eksperimental murni (true experiment). Populasi dalam penelitian ini adalah gigi premolar pertama rahang bawah manusia yang diekstraksi karena impaksi, pembuatan full denture, keperluan orthodontic dan lainnya. Sedangkan sampel penelitiannya adalah gigi premolar pertama rahang bawah dengan kriteria yaitu : gigi tidak karies, gigi belum pernah direstorasi, dan tidak fraktur.

Besar sampel yang dipakai pada setiap kelompok perlakuan pada penelitian ini adalah masing-masing sebesar 10 sampel. Kelompok I yaitu restorasi kavitas kelas II dengan restorasi sandwich $\mathrm{Ca}(\mathrm{OH})_{2}$, GIC dan resin komposit sebanyak 10 sampel. Sedangkan, kelompok II yaitu restorasi kavitas kelas II tanpa restorasi sandwich, dengan menggunakan $\mathrm{Ca}(\mathrm{OH})_{2}$ dan resin komposit sebanyak 10 sampel. Derajat kebocoran tepi restorasi ditentukan dengan mengamati perluasan penetrasi larutan disclosing solution pada sisi sepanjang tepi restorasi dan dinilai dengan menggunakan sistem penilaian standard dengan nilai 0-3 sesuai penelitian yang dilakukan Yazici et al (2003), yaitu : nilai $0=$ tidak ada penetrasi zat warna, nilail = penetrasi zat warna mencapai $1 / 2$ kedalaman kavitas, nilai $2=$ penetrasi zat warna melebihi $1 \frac{2}{2}$ kedalaman kavitas tanpa mencapai dinding axial kavitas, nilai $3=$ penetrasi zat warna mencapai dinding axial kavitas. Penelitian ini dilakukan pada tanggal 1 Oktober 2011 - 10 Oktober 2011 di Ruang Dasar Klinik Fakultas Kedokteran Gigi Universitas Mahasaraswati Denpasar, Bali.

Membuat outline form desain restorasi kelas II, digambar pada permukaan proksimal daerah distal gigi premolar, dengan ketentuan yaitu perluasan oklusal 3 $\mathrm{mm}$, perluasan bukal-lingual $3 \mathrm{~mm}$, dan gingival seat terletak pada $1 \mathrm{~mm}$ diatas cementoenamel junction. ${ }^{1}$
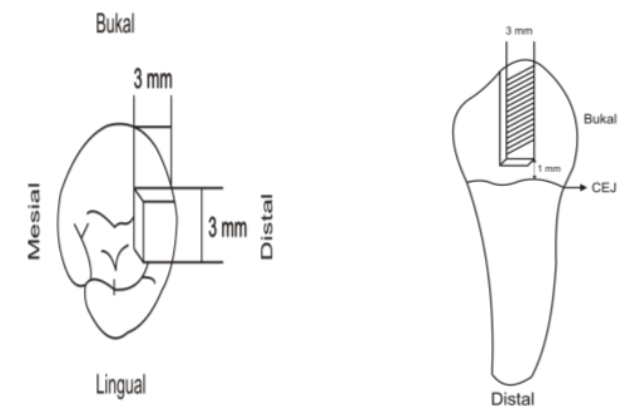

Gambar1. Desain preparasi kavitas kelas II pada gigi premolar pertama rahang bawah.

Dua puluh gigi premolar pertama rahang bawah dipreparasi dengan menggunakan diamond bur berkecepatan tinggi berbentuk round, fissure dan inverted. Sampel dikelompokkan secara acak menjadi 2 kelompok, dan ditanam dalam dua balok gips bersama gigi-gigi tetangganya untuk memudahkan pemasangan matriks dalam pembuatan dinding proksimal. ${ }^{10}$ Melakukan penumpatan dengan teknik sandwich pada kelompok pertama. Pada kavitas kelompok pertama, semua gigi dilapisi $\mathrm{Ca}(\mathrm{OH})_{2}$ pada atap pulpa. Kemudian setelah $\mathrm{Ca}(\mathrm{OH})_{2}$ kering, diaplikasi glass ionomer cement ke dalam kavitas \pm setebal $1 \mathrm{~mm}$. Setelah 24 jam, dilanjutkan dengan pengetsaan menggunakan asam fosfat $37 \%$ selama 15 detik kemudian dibilas dengan air selama 15 detik dan kelebihan air dikeringkan dengan menggunakan airway syringe kemudian bahan bonding diaplikasikan ke dalam kavitas, dan dilakukan light curing selama 20 detik. Kemudian kavitas ditumpat dengan menggunakan komposit dan di-light curing selama 30 detik. Setelah komposit mengeras, dilakukan pemolesan dengan pasta poles dan silikon rubber. Sedangkan, pada kelompok kedua, dilakukan perlakuan yang sama seperti kelompok I, hanya saja tidak dilakukan pengaplikasian glass ionomer cement. ${ }^{1}$ Kedua kelompok sampel tersebut direndam dalam larutan $\mathrm{NaCl}$ $0,9 \%$ selama 24 jam. ${ }^{1}$ Apeks seluruh sampel ditutup dengan sticky wax dan seluruh permukaan gigi dilapisi dengan 2 lapis cat kuku kecuali pada $1 \mathrm{~mm}$ disekitar tepi restorasi, kemudian dibiarkan mengering di udara terbuka hingga tidak terasa lengket. Kedua kelompok sampel tersebut direndam dalam larutan disclosing agent selama 24 jam pada suhu kamar. Seluruh permukaan gigi dibersihkan dengan air mengalir dan dikeringkan, kemudian memotong spesimen pada bagian tengah restorasi ke arah mesiodistal dengan menggunakan diamond disk. Mengamati penetrasi zat warna ke dalam tumpatan secara visual dan mencatat hasil penelitian. Data yang diperoleh dalam penelitian ini disajikan secara deskriptif.

\section{HASIL DAN DISKUSI}

Hasil penelitian terhadap kebocoran tepi pada restorasi sandwich dan pada restorasi resin komposit terlihat bahwa pada kelompok perlakuan dengan restorasi sandwich terlihat: 2 sampel bernilai 0,4 
sampel bernilai 1, dan 4 sampel memiliki nilai 2. Pada kelompok perlakuan dengan restorasi resin komposit, terdapat 6 sampel bernilai 2 dan 4 sampel bernilai 3 . Pada hasil pengamatan, terlihat bahwa kebocoran tepi lebih banyak terjadi pada dinding gingival.

Hasil uji statistik dengan one-sample kolmogorov-smirnov test terlihat bahwa nilai assymp.sig (0,072) lebih besar dari 0,05 (assymp.sig > 0,05), sehingga diasumsikan data terdistribusi normal. Oleh karena itu, data hasil pengamatan ini dapat dianalisis dengan menggunakan analisis statistik parametrik. Hasil rata-rata nilai kebocoran tepi pada kelompok perlakuan terlihat bahwa masing masing kelompok berjumlah 10 sampel yang terdiri dari kelompok restorasi resin komposit dengan rata-rata kebocoran tepi yaitu 2,4 sedangkan untuk kelompok restorasi sandwich memiliki rata-rata kebocoran tepi sebesar 1,2. Hasil ini menunjukkan bahwa nilai kebocoran tepi pada kelompok restorasi resin komposit lebih besar dibandingkan pada kelompok restorasi sandwich.

Hasil pengamatan secara visual dianalisa dengan Independent T-test untuk mengetahui perbedaan di antara kedua kelompok perlakuan terhadap kebocoran tepi. Hasil uji statistik dengan Independent T-test diketahui bahwa $t_{\text {hitung }}$ sebesar 4,025 , dengan p-value 0,001 . Hal ini menunjukkan $\mathrm{p}$-value $<0,05$, yang berarti terdapat perbedaan yang signifikan antara kelompok restorasi sandwich dengan kelompok restorasi resin komposit terhadap kebocoran tepi.

Hasil yang diperoleh dari penelitian ini menunjukkan bahwa restorasi sandwich memiliki kemampuan yang lebih baik dalam mencegah terjadinya kebocoran tepi pada restorasi kavitas kelas II bila dibandingkan dengan restorasi yang hanya menggunakan resin komposit. Hasil ini sejalan dengan penelitian yang telah dilakukan oleh Yuni dan Nurliza (2007), yang telah membedakan kebocoran tepi pada restorasi kavitas kelas $\mathrm{V}$ dengan restorasi sandwich teknik closed, open dan restorasi resin komposit. ${ }^{2,1}$

Penelitian ini menggunakan restorasi sandwich dengan teknik open, karena sesuai dengan penelitian yang telah dilakukan oleh Yuni dan Nurhaliza (2007) yang menyimpulkan bahwa restorasi sandwich dengan teknik open memiliki nilai kebocoran tepi yang lebih kecil dibandingkan dengan restorasi sandwich dengan teknik closed maupun restorasi resin komposit. Menurut Dharsono (2007), kavitas kelas II indikasi untuk restorasi sandwich dengan teknik open jika dinding gingivalnya terletak di daerah cementoenamel junction (CEJ). ${ }^{6,12}$

Glass ionomer cement pada restorasi sandwich dapat berikatan secara adhesif dengan struktur gigi. Adhesif merupakan daya tarik menarik antara antara molekul yang tidak sejenis pada dua permukaan yang berkontak. Sifat adhesif sangat penting untuk mencapai keberhasilan dalam penutupan daerah margin pada penyelesaian akhir suatu restorasi. ${ }^{11}$ Penutupan margin yang rapat dan tidak bocor dapat dihasilkan oleh sifat adhesif antara material restorasi dengan struktur gigi.
Sifat adhesif dari glass ionomer cement merupakan salah satu keuntungan karena daya adhesinya yang baik teradap dentin maupun email dapat mengatasi kebocoran mikro. ${ }^{12,13}$

\section{SIMPULAN}

Berdasarkan hasil penelitian terhadap kebocoran tepi pada restorasi sandwich dan restorasi resin komposit pada kavitas kelas II dapat disimpulkan bahwa ada perbedaan kebocoran tepi yang signifikan pada kelompok restorasi sandwich dengan kelompok restorasi resin komposit, yaitu kebocoran tepi pada kelompok restorasi sandwich lebih kecil dibandingkan dengan kelompok restorasi resin komposit.

\section{DAFTAR PUSTAKA}

1. Roberson TM. Sturdevant's Art and Science of Operative Dentistry. $4^{\text {th }}$ ed. St Louis; Mosby Co; 2002.

2. McCabe JF. Applied Dental Materials. $9^{\text {th }}$ ed. Australia; Blackwell: 2008.

3. Motamedi, et al. Comparison of MTA and GlassIonomer Microleakage in Two Open and Closed Sandwich Techniques in Class II Composite Resin Restorations. Research Journal Biological Sciences 2011; 6(7); 327-332.

4. Baum L, Phillips RW, Lund MR. Buku Ajar Ilmu Konservasi Gigi. Tarigan R (Penterjemah) Jakarta; EGC; 1997.

5. Nurhaliza C, Yuni.. Pengamatan kebocoran mikro restorasi sandwich teknik open dan closed pada restorasi kelas V. Dentika Dental Jurnal 2007; 12(1); 44-48.

6. Baum L, Phillips RW, Lund MR. Buku Ajar Ilmu Konservasi Gigi. Tarigan R (Penterjemah) Jakarta; EGC; 1997.

7. Kenneth J A. Phillips'Science of Dental Material. $11^{\text {th }}$ ed. St. Louis; Saunders Elsevier; 2003.

8. Marhant, et al. Marginal quality and microleakage of adhesive class V restorations. J Dent 2001.

9. Dharsono HDA, Restorasi Resin Komposit dengan Teknik Laminasi [serial online] Agst 2007. Available from: http://resources.unpad.ac.id/unpadontent/uploads/publikasi_dosen/ restorasi resin komposit dengan teknik laminasi.pdf.Accessed Agustus 18, 2011.

10. Riwidikdo H. Statistik untuk Penelitian Kesehatan. Ed. Ke 2, Yogyakarta; Pustaka Rihama; 2010.

11. Radhika M, Kumaraswamy BN, Neetu M. Effect of different placement techniques on marginal microleakage of deep class-II cavities restored with two composite resin formulations. J Conserv Dent 2010; 13(1); 9-15.

12. Van Noort R. introduction to Dental Materials. London; Mosby Co; 1994; 34-35, 61-71, 89-105.

13. Adiana ID. Semen Ionomer Kaca Sebagai Bahan Pelapik Pada Restorasi Sandwich. Skripsi. Medan: Universitas Sumatera Utara: 2004. 